\title{
LA REGIÓN DE MURCIA EN LOS MANUALES ESCOLARES DE EDUCACIÓN SECUNDARIA. UNA NARRATIVA A LA SOMBRA DE ESPAÑA Y EUROPA*
}

\author{
The region of Murcia in secondary education textbooks. \\ A narrative in the shadow of Spain and Europe
}

\section{Raimundo A. Rodríguez Pérez ${ }^{\varnothing}$, María del Mar Simón García ${ }^{\S}$ y Sebastián Molina Puche ${ }^{ð}$}

Fecha de recepción: 05/09/2016 • Fecha de aceptación: 14/12/2016

Resumen. Los manuales escolares de ciencias sociales son la narrativa histórica más leída, en muchos casos la única para gran parte de la población en toda su vida. De ahí la necesidad de analizar al detalle qué tipo de contenidos y actividades contienen. La preeminencia del libro de texto como principal recurso educativo en España sigue siendo abrumadora, tanto en Educación Primaria como Secundaria. Ello deriva del modelo conceptual asignado a materias humanísticas como la historia. Junto con la lección magistral y el examen memorístico, el manual nos explica los avances y retrocesos en la enseñanza de la historia en España. Los estudios sobre cuestiones identitarias y narrativas de corte nacional son muy abundantes. Pero se echa en falta un acercamiento al papel asignado en los manuales a las distintas comunidades autónomas, desde que se transfieren las competencias educativas a las mismas. Su relevancia cuantitativa y cualitativa, frente a los contenidos estatales y universales (eurocéntricos), es mucho menor y las últimas leyes han supuesto un retroceso. La aproximación al caso de la Región de Murcia pretende desvelar la continuidad de tópicos que simplifican y falsean la historia de este territorio, impidiendo que los estudiantes adquieran un mínimo bagaje sobre la diversidad de

\footnotetext{
"El presente trabajo ha sido desarrollado en el marco de los proyectos: EDU2015-65621-C3-2-R, financiado por el Ministerio de Economía y Competitividad; y 18951/JLI/13, financiado por la Fundación Séneca. Agencia de Ciencia y Tecnología de la Región de Murcia.

ø Departamento de Didáctica de las Ciencias Matemáticas y Sociales. Facultad de Educación. Universidad de Murcia. Campus de Espinardo. 30100 Espinardo (Murcia). raimundorodriguez@um.es.

$\S$ Departamento de Didáctica de las Ciencias Matemáticas y Sociales. Facultad de Educación. Universidad de Murcia. Campus de Espinardo. 30100 Espinardo (Murcia).mmar.simon@um.es.

` Departamento de Didáctica de las Ciencias Matemáticas y Sociales. Facultad de Educación. Universidad de Murcia. Campus de Espinardo. 30100 Espinardo (Murcia). smolina@um.es.
}

Cómo citar este artículo: Rodríguez Pérez, Raimundo R., Simón García, María del Mar y Molina Puche, Sebastián. «La Región de Murcia en los manuales escolares de educación secundaria. Una narrativa a la sombra de España y Europa», Historia y Memoria de la Educación, 6 (2017): 241-277. 
paisajes, culturas y formas de vida. Para ello se analizan nueve manuales de historia de $1 .^{\circ}, 2 .^{\circ}$ y $4 .^{\circ}$ de Educación Secundaria Obligatoria, que abarcan las dos últimas décadas y tres leyes educativas (LOGSE, LOE y LOMCE).

Palabras clave: Manual escolar; Educación Secundaria; Enseñanza de la historia; Región de Murcia.

Abstract. Social science textbooks are the most widely read historical narrative, and for much of the population constitute the only reading they will ever have done on the subject. Hence the need to analyze in detail what types of content and activities these books contain. The pre-eminence of textbook as the main educational resource in Spain remains overwhelming, both in primary and secondary education. This derives from the conceptual model assigned to humanistic subjects like history. Along with the lecture and rote examination, the manual gives us a picture of the advances and setbacks in the teaching of history in Spain. While studies on issues regarding national identity and narrative are abundant, there is a conspicuous lack of coverage in the manuals of the different autonomous communities since educational power was transferred to them. In both quantitative and qualitative terms, the relevance given to the regions is far inferior to that given to state and universal contents (Eurocentric), and the latest laws have only led to more of a setback. Our examination of the case of the Region of Murcia seeks to reveal the continuity of clichés that simplify and distort the history of this territory, preventing students from acquiring a minimum background knowledge of the region's diversity of landscapes, cultures and lifestyles. To this end we have analyzed nine history textbooks of the 1st, 2nd and 4th years of Secondary Education, covering the last two decades and three most recent education laws (LOGSE, LOE and LOMCE).

Key words: Textbook; Secondary Education; Teaching history; Region of Murcia.

\section{LA ACTUAL REGIÓN DE MURCIA: UNA HISTORIA COMPLEJA Y UNA IDENTIDAD DÉBIL}

La historia local y regional no debe ser un fin en sí mismo, pero sí puede ayudar a entender el pasado y el presente. En 1979 Pérez Picazo, Lemeunier y Chacón afirmaban que «Murcia no tiene historia». ${ }^{1}$ Era evidentemente una provocación; lo que no tenía era casi historiografía, sal-

\footnotetext{
${ }^{1}$ María Teresa Pérez Picazo, Guy Lemeunier y Francisco Chacón Jiménez, Materiales para una historia del Reino de Murciaen los tiempos modernos (Murcia: Universidad de Murcia, 1979), 9.
} 
vo para la época medieval, gracias al profesor Torres Fontes. ${ }^{2}$ En cuanto a fuentes impresas tipo crónicas del antiguo reino murciano, son escasas y tardías en comparación con otros territorios peninsulares. Destacan los Discursos Históricos del licenciado Cascales (1621), ${ }^{3}$ epítome de la ciudad y todo su reino. La actual Región de Murcia como tal no surge hasta el 9 de junio de 1982, cuando se aprueba su estatuto autonómico, es decir apenas 34 años de vida la contemplan. Por tanto, hablar de Región de Murcia al analizar la Prehistoria, Antigüedad, Edad Media, Moderna y buena parte de la época contemporánea resulta cuando menos presentista.

Por el contrario, desde la Edad Media hasta 1833, cuando surgen las actuales demarcaciones provinciales (de la mano del ministro Javier de Burgos), sí se puede hablar de reino de Murcia. Un territorio de más de 20.000 kilómetros cuadrados, el doble que los poco más de 11.000 de la región uniprovincial actual. Incluía una serie de territorios que durante siglos fueron murcianos, pero en el XIX pasan a integrar las provincias de Jaén, Almería, Alicante y, sobre todo, Albacete, a fin de que estas consiguieran el mínimo de población para formar provincia propia. A esos límites regnícolas se superpone otra división administrativa no menos relevante: la diócesis de Cartagena, aún más extensa que el antiguo reino, de hecho hasta mediados del XVI incluía la gobernación de Orihuela (gran parte de la provincial actual de Alicante) y hasta mediados del siglo XX no se crea el obispado de Albacete. La diversidad de comarcas y paisajes de la actual Región de Murcia no oculta un sustrato común, conformado a partir del surgimiento del reino cristiano, en el siglo XIII, tal y como han señalado especialistas en historia económica, medieval y moderna. ${ }^{4}$ La carencia de lengua propia no es óbice para la existencia de

\footnotetext{
2 Juan Torres Fontes, Fajardo el Bravo (Murcia: Universidad de Murcia, 1944); Don Pedro Fajardo, Adelantado Mayor del Reino de Murcia (Madrid: CSIC, 1953), Repartimiento de Murcia (Murcia: Academia Alfonso X el Sabio, 1960), y Repartimiento de Lorca (Murcia: Ayuntamiento de Lorca y Academia Alfonso X el Sabio, 1977).

${ }^{3}$ Francisco Cascales, Discursos históricos de la Muy Noble y Muy Leal Ciudad de Murcia (Murcia: Luis de Berós, 1621).

${ }^{4}$ María Teresa Pérez Picazo y Guy Lemeunier, El proceso de modernización en la Región murciana (siglos XVI-XIX) (Murcia: Editora Regional, 1984); Miguel Rodríguez Llopis, Historia de la Región de Murcia (Murcia, Editora Regional, 1994); Miguel Rodríguez Llopis (dir.) y José Miguel Martínez Carrión (coord.), Atlas histórico ilustrado de la Región de Murcia y su antiguo reino (Murcia: Fundación Séneca, 2006); Juan Francisco Jiménez Alcázar, «Identificación e identidad en el desarrollo de la memoria histórica: el reino de Murcia y la Edad Media», Historia y Genealogía, 2 (2012): 175-199.
} 
un dialecto, que los murcianos llevan consigo cuando repueblan comarcas almerienses como los Vélez y el Almanzora en el siglo XVI, o bien las nuevas poblaciones de la Vega Baja del Segura en el XVIII, a instancias del obispo Belluga. ${ }^{5}$ También unos cánones artísticos que se extienden desde el norte de la actual provincia de Albacete hasta comarcas almerienses, granadinas y alicantinas evidencian una estética común en la arquitectura (las obras de Jerónimo Quijano en el XVI, ${ }^{6}$ el prototipo de iglesia barro$\mathrm{ca}^{7}$ de una sola nave, el modelo de casonas nobiliarias también barroco, ${ }^{8}$ el modernismo cartagenero ${ }^{9}$ ), las artes figurativas (la pintura del XVII, ${ }^{10}$ Salzillo y su escuela imaginera, ${ }^{11}$ un siglo después), las artes decorativas, ${ }^{12}$ la orfebrería ${ }^{13}$ y la artesanía. ${ }^{14}$ Si bien muchas monografías sobre cuestiones patrimoniales no aparecen hasta las décadas de 1980 y 1990, a raíz del surgimiento de la demarcación autonómica y el impulso de instituciones como la Universidad de Murcia. Toda carencia historiográfica no es sino una carencia de investigación; en este caso se demuestra la importancia de escuelas artísticas que tuvieron como epicentro Murcia, Cartagena o Lorca desde la baja Edad Media.

\footnotetext{
${ }^{5}$ Mercedes Abad Merino, Lenguas en contacto y cambio de lengua en una ciudad bilingüe: Orihuela, siglo XVII (Murcia: Universidad de Murcia, 1993); y «La frontera lingüística murciano-andaluza desde una perspectiva diacrónica», Tonos digital: Revista electrónica de estudios filológicos, 3 (2002), consultado el 10 de mayo de 2016, URL: http://www.um.es/tonosdigital/znum3/estudios/LaFronteraPLANT.htm

${ }^{6}$ Cristina Gutiérrez-Cortines Corral, Renacimiento y arquitectura religiosa en la antigua diócesis de Cartagena (Reyno de Murcia, Gobernación de Orihuela y Sierra del Segura) (Murcia: Colegio de Aparejadores y Arquitectos Técnicos, 1987).

${ }^{7}$ Cristóbal Belda Navarro y Elías Hernández Albaladejo, Arte en la Región de Murcia. De la Reconquista a la Ilustración (Murcia: Editora Regional, 2006), 303-334.

${ }^{8}$ Pedro Segado Bravo, Lorca Barroca. Arquitectura y arte (Murcia: Editum, 2012), 367-460.

${ }^{9}$ Francisco Javier Pérez Rojas, Cartagena 1874-1936 (Transformación urbana y arquitectura) (Murcia, Editora Regional, 1986), 214-360.

10 José Carlos Agüera Ros, Pintura y sociedad en el siglo XVII. Murcia, un centro del Barroco español (Murcia: Real Academia Alfonso X el Sabio, 1994).

${ }^{11}$ José Sánchez Moreno, Vida y obra de Francisco Salzillo. Una escuela de escultura en Murcia (Murcia: Nogués, 1945).

12 Manuel Pérez Sánchez, El arte del bordado y del tejido en Murcia, siglos XVI-XIX (Murcia: Universidad de Murcia, 1999).

13 José Carlos Agüera Ros, Platería y plateros seiscentistas en Murcia (Murcia: Universidad de Murcia, 2005).

${ }^{14}$ Manuel Jorge Aragoneses, Artes industriales cartageneras: lozas del siglo XIX (Cartagena: Museo Arqueológico Municipal, 1960); y El mueble popular en Murcia (1866-1933). Consideraciones acerca de su entidad estética y funcional (Murcia: Academia Alfonso X el Sabio, 1982).
} 
La escasa identidad regional de los murcianos tiene que ver con su peculiar centralismo y su condición de reino triplemente fronterizo (por tanto pobre y despoblado) durante siglos con Aragón, el Mediterráneo y, sobre todo, Granada. El hecho de que la ciudad de Murcia tuviese todo el protagonismo institucional impidió articular una identidad plural, pues en ella tenían su sede el obispado, el adelantamiento y la capitanía mayor del reino, el corregimiento (hasta el XVII no se segrega Lorca y una centuria después Cartagena), el tribunal inquisitorial y la provincia fiscal. La representación política del reino pasaba sólo por la oligarquía de su capital, única ciudad con voto en las cortes de Castilla, de forma que las familias poderosas del resto de poblaciones relevantes acababan instalándose en Murcia para su promoción social. Los territorios actualmente andaluces y manchegos, alejados del centro de poder regnícola, nunca se sintieron demasiado integrados, muchos de ellos eran señoríos de la Orden de Santiago o de diversas familias de la nobleza (los Vélez), ${ }^{15} \mathrm{o}$ formaban parte del corregimiento de Chinchilla-Villena, ${ }^{16}$ por tanto contaban con su propia jurisdicción civil o religiosa. ${ }^{17}$

En las últimas dos décadas ha emergido una identidad regional en torno a temas como el agua, o mejor dicho su escasez, paradigma de construcción identitaria en negativo, esto es por oposición a los que negaban trasvases al sureste español, en especial a la Comunidad Autónoma de Murcia, aunque también se incluye Alicante y Almería; a saber, Castilla-La Mancha, Aragón y Cataluña. En algunos de esos territorios se ha dado el fenómeno inverso, toda una metáfora del Estado de las autonomías. Aunque no es nada nuevo que la construcción identitaria se fortalece a base de buscar enemigos o rivales. De este modo los relatos emanados de los poderes fácticos consolidan una legitimidad débil, debido a la corta trayectoria de la entidad autonómica, toda vez que generan autoestima entre la sociedad, al servir de objetivo común que perseguir.

Pensar que las reducidas dimensiones de una región como la murciana la exoneran de un pasado relevante es un error grave, además de

\footnotetext{
15 Raimundo A. Rodríguez Pérez, El camino hacia la corte. Los marqueses de Los Vélez en el siglo XVI (Madrid: Sílex, 2011).

16 Sebastián Molina Puche, «El gobierno de un territorio de frontera: corregimiento y corregidores de Chinchilla, Villena y las nueve villas, 1586-1690», Investigaciones históricas, 25 (2005): 55-84.

17 Juan Bautista Vilar, El proceso de vertebración territorial de la Comunidad de Murcia: de reino a autonomía uniprovincial (Murcia: Consejo Jurídico de la Región de Murcia, 2003).
} 
engañoso, pues se trata de una de las diez provincias más habitadas del territorio nacional. En la actual demarcación autonómica se han desarrollado algunos eventos de gran importancia: La Bastida de Totana ${ }^{18}$ (época argárica) fue la ciudad fortificada más antigua de Europa occidental (2200 a.C.); la segunda guerra púnica tuvo uno de sus escenarios principales con la conquista romana de Carthago Nova (209 a.C.); ${ }^{19}$ Murcia fue la taifa musulmana más importante de Sharq Al Ándalus durante el siglo XII; ${ }^{20}$ las minas de Mazarrón abastecían de alumbre las manufacturas textiles del norte de Europa, en el siglo XVI; ${ }^{21}$ los moriscos del valle de Ricote fueron los últimos expulsados de España, en 1614; ${ }^{22}$ la decisiva batalla de Almansa durante la Guerra de Sucesión (1707); ${ }^{23}$ el cantón de Cartagena $^{24}$ (1873-1874). Algunos destacados personajes son oriundos de este territorio: San Isidoro, Ibn Arabí, Pedro de Orrente, Saavedra Fajardo, Melchor de Macanaz, Isaac Peral, Juan de la Cierva... En suma, analizar cuestiones regionales o locales no significa aterrizar en contenidos secundarios.

La existencia de un territorio con unas fronteras relativamente estables, desde las segundas taifas hasta 1833, no ha sido motivo suficiente para generar una identidad fuerte. Al ser un reino periférico y poco poblado surgieron escasas demarcaciones concejiles (sólo 45 en la actual autonomía), muchas de ellas de gran amplitud (marquesado de Villena al norte, encomiendas santiaguistas en el centro y concejos de realengo al sur). Las élites políticas y religiosas estuvieron fuertemente imbricadas

18 Vicente Llull, et al., "Proyecto La Bastida": economía, urbanismo y territorio de una capital argárica», Verdolay: Revista del Museo Arqueológico de Murcia, 13 (2011): 57-70.

${ }^{19}$ Sebastián F. Ramallo y María Milagrosa Ros, «De "Qart Hadast" a "Carthago Nova": la conquista de Escipión como trasfondo», en Los Escipiones: Roma conquista Hispania, coord. Manuel Bendala Galán (Madrid: Museo Arqueológico Regional de Alcalá de Henares, 2015), 163-179.

${ }^{20}$ Pedro Jiménez Castillo, «Murcia. De la Antigüedad al Islam» (Tesis doctoral, Universidad de Granada, 2013), 205-220; Alfonso Robles Fernández, «Estudio arqueológico de los palacios andalusíes de Murcia (ss. X-Xv). Tratamiento ornamental e influencia en el entorno» (Tesis doctoral, Universidad de Murcia, 2016), 194-230.

${ }^{21}$ Alfonso Franco Silva, El alumbre del Reino de Murcia. Una historia de ambición, intrigas, riqueza y poder (Murcia: Real Academia Alfonso X el Sabio, 1996); Felipe Ruiz Martín, Los alumbres españoles: un índice de la coyuntura económica europea en el siglo XVI (Madrid: Fundación Española de Historia Moderna, 2005).

22 José María García Avilés, Los moriscos del Valle de Ricote (Alicante: Universidad de Alicante, 2007).

${ }^{23}$ Francisco García González (coord.), La Guerra de Sucesión en España y la batalla de Almansa. Europa en la encrucijada (Madrid: Sílex, 2009).

${ }^{24}$ María-Alice Medioni, El Cantón de Cartagena (Madrid: Siglo XXI, 1979). 
en la administración central, a pesar del alejamiento. Sin embargo, ese atraso tampoco ha sido usado como agravio reivindicativo frente al poder estatal, como en otras regiones no tanto nacionalistas sino regionalistas (Galicia, Andalucía), con las que Murcia presenta otro rasgo común: la emigración masiva (hacia Cataluña, Europa occidental) como válvula de escape al desigual reparto de la propiedad y tardía industrialización..$^{25} \mathrm{La}$ ausencia de lengua propia tampoco se vio suplida por una literatura de temática murciana; es decir se ha hecho literatura en Murcia, no de Murcia (salvando al poeta Vicente Medina), ${ }^{26}$ al no existir un Blasco Ibáñez o una Rosalía de Castro. Tampoco hay un patronazgo religioso o himno regional, ni un ideólogo de las reivindicaciones identitarias; incluso el escudo y bandera son creaciones recientes, forzadas por el surgimiento del ente autonómico.

Las fuertes identidades locales (Cartagena, Caravaca, Lorca, Yecla), con influencias en comarcas de provincias limítrofes, y el secular atraso en comunicaciones e infraestructuras han impedido una identidad regional cohesionada. Si su evolución histórica es poco conocida por los propios murcianos, ni que decir tiene en el resto de España. El gentilicio idéntico al de la capital autonómica es otro obstáculo, dada la confusión que genera con el conjunto de la región. Esto no significa que sea una autonomía nefasta, sino que aún se encuentra en su andadura inicial como proyecto colectivo. Salvando las enormes distancias, y sin interés ideológico alguno, esto puede asemejarse a la famosa frase del ministro italiano Massimo D'Azeglio en 1870, tras culminarse la unificación de su país: "ya tenemos Italia; ahora hay que crear italianos» ${ }^{27}$ (faltaría crear «murcianos»).

\section{DECRETOS Y MANUALES DE HISTORIA EN EDUCACIÓN SECUNDARIA}

Valls Montés ha señalado cuatro etapas en la evolución del currículo de historia en Educación Secundaria. ${ }^{28}$ La primera (1836-1890) supo-

\footnotetext{
${ }_{25}$ José Álvarez Junco, Dioses útiles. Naciones y nacionalismos (Barcelona: Galaxia Gutenberg, 2016), 252-282.

${ }^{26}$ Francisco Javier Díez de Revenga y Mariano de Paco, Historia de la literatura murciana (Murcia: Universidad de Murcia, Academia Alfonso X el Sabio y Editora Regional, 1989), 330-339.

27 Álvarez Junco, Dioses útiles, 12.

${ }^{28}$ Rafael Valls Montés, Historiografía escolar española: siglos XIX-XXI (Madrid: UNED, 2007), 55-63.
} 
ne la creación del código disciplinar, en el cual predominaba la memoria frente al razonamiento y los contenidos principales serán relativos a nombres, fechas y batallas, algo que casi dos siglos después aún mantiene su carácter hegemónico. ${ }^{29}$ La segunda (1880-1939) destaca por el predominio de la historiografía positivista y europeísta, de la cual emerge la primera escuela historiográfica, con autores como Rafael Altamira. La Segunda República apenas podrá implantar unos manuales verdaderamente renovadores, de modo que seguirá usando los preexistentes. Este modelo positivista y memorístico aún sigue impregnando currículos, manuales y evaluaciones en la actualidad. ${ }^{30}$ La tercera (1939-1970) implica un retroceso, con el rechazo a la modernidad educativa, reflejado en unos manuales cuya función era exaltar los valores católicos y patrióticos del franquismo, obviando todo lo ligado a una visión europeísta, laica o liberal. ${ }^{31}$

La cuarta (1975-actualidad) es en la que se ubica este estudio. Está marcada por la necesidad de un nuevo código disciplinar y las desavenencias sobre su concreción. Destaca el cambio de rumbo, de un modelo nacionalcatólico a otro más tecnicista, a partir de 1970, con la Ley General de Educación (LGE). Va a primar la formación de ciudadanos pertenecientes a una nación que estaba incorporándose, por fin, al modelo de bienestar occidental y ampliaba la educación obligatoria hasta los catorce años. Comienzan a cobrar relevancia la educación por objetivos, el entorno del alumnado, la vida cotidiana o los trabajos de campo. La influencia de Piaget marcará unos contenidos que van de lo cercano a lo lejano, ${ }^{32}$ algo que no obstante hace ya varias décadas se viene poniendo en duda para la enseñanza de la historia. ${ }^{33}$

${ }^{29}$ Consuelo Delgado y Catalina Albacete, Conocimiento del medio social y cultural (Murcia: Diego Marín, 2006), 6-13.

30 José Monteagudo Fernández, Pedro Miralles Martínez y José Luis Villa Arocena, Evaluación de la materia de Historia. El caso de la Región de Murcia (Saarbrücken: Publicia, 2014), 148-159.

${ }^{31}$ Rafael Valls Montés, Historia y memoria escolar. Segunda República, Guerra Civil y dictadura franquista en las aulas (Valencia: PUV, 2009), 41.

32 Roser Canals y Neus González, «El Currículo de Conocimiento del Medio Social y Cultural, y la formación de competencias», en Didáctica del Conocimiento Social y Cultural en la Educación Primaria: ciencias sociales para aprender, pensar y actuar, coords. Antoni Santisteban y Joan Pagès (Madrid: Síntesis, 2011), 41-62.

${ }^{33}$ Antonio Calvani, L'insegnamento della storia nella scuola elementare (Florencia: La Nuova Italia, 1986); Kieran Egan, La comprensión de la realidad en la educación infantil y primaria (Madrid: Morata, 1991). 
En 1990 la Ley de Ordenación General del Sistema Educativo (LOGSE) supone un modelo curricular abierto y flexible - frente a la tradición anterior- que dejaba en manos de autonomías y centros escolares la concreción de programas. En relación a la historia, destaca la insistencia en cambios y continuidades, así como en cuestiones culturales. La edad de escolaridad obligatoria aumenta de los catorce a los dieciséis años, equiparando España con los países europeos. Los contenidos se dividen en conceptuales, procedimentales y actitudinales, aunque serán los primeros los que sigan predominando hasta la actualidad de forma abrumadora. Pero se observa ya un interés por cuestiones no sólo memorísticas y teóricas, además de subrayar la educación en valores. En Educación Secundaria surgirá el área de Ciencias Sociales, integrada por los contenidos de Geografía e Historia.

La Ley Orgánica de Calidad de la Educación (LOCE) y la Ley Orgánica de Educación (LOE), en 2002 y 2006 respectivamente, han venido matizando aspectos pedagógicos, que en general han afectado poco a los contenidos y sistemas de evaluación aplicados en las aulas de historia, a pesar de la inclusión de la evaluación por competencias en 2006, que en la práctica resulta ajena a buena parte de los docentes, aunque afirmen aplicarla en cuestionarios o investigaciones. Se promueve un aprendizaje que evalúe no sólo la cantidad, sino la calidad y por supuesto el saber hacer, es decir las capacidades. Esto no ha servido para desplazar al modelo tradicional de reproducción de conocimientos. La recién aprobada LOMCE aporta como novedad los estándares de aprendizaje, contenidos relativos a la iniciativa emprendedora y refuerza la idea de una narrativa nacional española. ${ }^{34}$

La idea de España ha vertebrado la enseñanza de la historia desde el siglo XIX. En esta fase inicial no se distingue del resto de Estados-nación europeos, empeñados en crear ciudadanos y patriotas que asuman una lengua e identidad comunes. Aunque en España el Estado pronto renunció a tutelar ese proceso mediante centros públicos, dejando en manos de órdenes y congregaciones religiosas la formación de las élites y las clases populares. ${ }^{35} \mathrm{La}$ influencia religiosa hará que, en los contenidos re-

\footnotetext{
${ }^{34}$ Ramón López Facal, «La LOMCE y la competencia histórica», Ayer, 94 (2014): 273-285.

${ }^{35}$ Antonio Viñao Frago, Política y educación en los orígenes de la España contemporánea. Examen especial de sus relaciones en la enseñanza secundaria (Madrid: Siglo XXI, 1982); y Escuela para todos. Educación y modernidad en la España del siglo XX (Madrid: Marcial Pons, 2004).
} 
lativos al origen de la humanidad, no se incorporen hasta fechas tardías las novedades de la arqueología y el evolucionismo, que chocaban con los relatos bíblicos. La Institución Libre de Enseñanza, vanguardia de la modernización educativa y ajena al modelo dominante, rechazaba el uso del manual en los niveles primarios, favoreciendo la enseñanza oral. ${ }^{36}$

Hasta la década de 1970, los manuales ensalzaron como positivas las épocas de unidad territorial: Roma, visigodos, Reyes Católicos. Tanto los más tradicionalistas como los liberales concedieron a los Reyes Católicos la condición de creadores de la patria, ${ }^{37}$ algo falso porque se trataba de una unión dinástica. La LGE (1970) impulsa una educación obligatoria de los 6 a los 14 años (EGB), seguida de tres años de bachillerato (BUP) y el curso de orientación universitaria (COU). Esta etapa viene marcada por el fin del nacionalismo historiográfico, dado que en ese momento interesaba sumarse al Mercado Común europeo. Se sustituye la explicación positivista, de corte político, por otra global (social, económica) propia de la revista Annales. Los viejos enemigos (musulmanes, ingleses, franceses) son sustituidos por el comunismo.

En las décadas de 1970 y 1980 los manuales comienzan a ser elaborados por historiadores o especialistas en didáctica de prestigio, o bien profesores de educación secundaria. Con todo, pervivieron tópicos nacionalistas, centrados en mostrar una evolución histórica con unas fronteras comunes desde la Antigüedad, dando una idea falsa de continuidad. A partir de 1975 destaca la aparición de grupos didácticos (Germanía 75, Cronos, 13-16, Ínsula Barataria), que sustituyen el modelo narrativo tradicional por uno más interpretativo o metodológico, defendiendo el mayor protagonismo del alumnado y la recopilación de fuentes primarias. Consiguieron cierta repercusión y críticas al desplazar los tradicionales contenidos, pero fueron minoritarios. ${ }^{38}$

Las presiones políticas, editoriales y académicas dejaron la idea de «currículo abierto» de la LOGSE en una quimera. En la práctica, los «contenidos mínimos» eran tan amplios que seguían marcando una pro-

\footnotetext{
${ }^{36}$ Joaquín García Puchol, Los textos escolares de historia en la enseñanza española (1808-1900). Análisis de su estructura y contenido (Barcelona: Universidad de Barcelona, 1992), 26.

${ }^{37}$ Ramón López Facal, «Nacionalismos y europeísmos en los libros de texto: identificación e identidad nacional», Clío y asociados: la historia enseñada, 14 (2010): 11-13.

${ }^{38}$ Valls Montés, Historiografía escolar española, 60-62.
} 
gramación extensa, donde reconocer los hitos fundamentales del pasado. La ampliación de la enseñanza obligatoria hasta los dieciséis años supuso implantar el sistema todavía vigente: cuatro años de Educación Secundaria Obligatoria (ESO) y dos de Bachillerato. En el segundo de estos últimos destacaba la existencia de una asignatura obligatoria de Historia de España, centrada en la etapa contemporánea, algo anómalo en relación al resto de Europa, fruto del contexto político interno. ${ }^{39}$ Los contenidos que reflejan los manuales, sobre todo a partir de la década de 1990, suponen un salto cualitativo, por ajustarse más a lo que se investiga en historia en las universidades, así como la inclusión de fuentes y documentos de cada época tratada. Además, otra gran novedad fue la inclusión de lo local en currículos y manuales, aunque nunca superando el 10\% respecto a la historia nacional. La polémica se suscitó por la sustitución de tópicos españolistas por los de los nacionalismos periféricos, catalán y vasco sobre todo. Esto motivó una ofensiva recentralizadora, a favor de la clásica historia general de España. A partir de la LOCE (2002) y, sobre todo, de la LOE (2006) se pierde el modelo abierto y flexible. Esto explica por qué los manuales siguen incluyendo tan vasto temario, pues se concentra toda la historia universal y nacional en pocos cursos.

Actualmente la extensión y complejidad de los temas históricos reflejados en los manuales se ha reducido tanto en la enseñanza primaria como secundaria. Debido a los cambios sociales y culturales, las editoriales ya no hacen hincapié en cuestiones conflictivas, que son eliminadas o idealizadas, aunque persiste el protagonismo de lo político-factual. En cuanto a las actividades, se perciben casi las mismas preguntas que años atrás, cambiando el nombre del epígrafe final de cada tema por el de Practica tus competencias, aunque la información que se pide al alumno sigue siendo en esencia memorística. ${ }^{40}$ Con la LOMCE (2013), la enseñanza de la historia se inicia a partir de $4 .^{\circ}$ de Educación Primaria, con una impronta nacional, que ha reducido aún más las páginas dedicadas a la autonomía de turno. En la ESO, donde aún no se ha implantado por completo la última reforma educativa, la visión es más eurocéntrica,

\footnotetext{
${ }^{39}$ López Facal, «Nacionalismos y europeísmos», 10.

${ }^{40}$ Raimundo A. Rodríguez Pérez, Cosme Jesús Gómez Carrasco y María del Mar Simón García, «Conocimiento y pensamiento histórico en los manuales escolares de tercer ciclo de Primaria. Un análisis comparativo", en Investigación educativa en Educación Primaria, eds. Rosa Nortes Martínez-Artero y José Ignacio Alonso Roque (Murcia: Editum, 2014), 369-380.
} 
pero dominada igualmente por la evolución lineal: Prehistoria y Antigüedad (primer curso), Edad Media (segundo curso), Edad Moderna (tercer curso), Edad Contemporánea (cuarto curso).

Los estudios sobre los libros de texto constituyen una línea de investigación clásica en la didáctica de las ciencias sociales. ${ }^{41}$ La perspectiva sociocultural, que centra su investigación en el conocimiento pedagógico de los contenidos mostrados en los libros de texto, es la que más ha primado en los estudios sobre los manuales escolares. ${ }^{42}$ Actualmente su análisis ha adquirido mayor complejidad al estudiarse tanto sus características internas como el contexto de uso por parte de profesores y alumnos. Muchos maestros aún tienen el libro de texto como única referencia del saber histórico, del que apenas se apartan ni en clase ni a la hora de plantear actividades. Los resultados de algunas investigaciones muestran que el 95\% de los exámenes analizados proceden literalmente de la propuesta del manual, en el caso de Educación Primaria. ${ }^{43}$ El discurso transmitido se basa en la construcción de la narrativa histórica de España, en mucha menor medida interesa lo europeo o lo universal. Dicho discurso se complementa con un epígrafe dedicado a la comunidad autónoma de turno, que en la Educación Primaria aparece a título casi anecdótico, y más que en la historia suele centrarse en aspectos culturales, sobre todo del patrimonio material. ${ }^{44}$

Los estudios sobre percepciones del alumnado en Educación Secundaria subrayan el predominio del uso del manual como clave de una recepción pasiva de los saberes históricos. Hasta un 80\% del alumnado analizado afirma que era el recurso didáctico fundamental. Junto a la lección magistral, ausencia de debates y predominio de exámenes escritos

${ }^{41}$ Rafael Valls Montés, «Los estudios sobre manuales escolares de historia y sus nuevas perspectivas», Didáctica de las ciencias experimentales y sociales, 15 (2001): 23-36; Joaquim Prats, "Criterios para la elección del libro de texto de historia», Íber: Didáctica de las ciencias sociales, geografía e historia, 70 (2011): 7-13.

${ }^{42}$ Nicolás Martínez Valcárcel, «El uso de los manuales escolares de historia de España. Análisis de resultados desde la propuesta de Schulman», Íber: Didáctica de las ciencias sociales, geografía e historia, 70 (2011): 44-58.

${ }^{43}$ Cosme Jesús Gómez Carrasco, Raimundo A. Rodríguez Pérez y Pedro Miralles Martínez, «La enseñanza de la historia en Educación Primaria y la construcción de una narrativa nacional. Un estudio sobre exámenes y libros de texto en España», Perfiles Educativos, 37 (150), (2015): 20-38.

${ }^{44}$ Raimundo A. Rodríguez Pérez y María del Mar Simón García, «La construcción de la narrativa nacional española en los manuales escolares de Educación Primaria», Ensayos, 29 (1), (2014): 101-113. 
memorísticos, denota unas metodologías docentes arcaicas. ${ }^{45}$ Los ejercicios de empatía histórica, principalmente tratados en el ámbito anglosajón, ${ }^{46}$ movilizan otro tipo de habilidades cognitivas sobre historia, pero brillan por su escasez en manuales tanto de Educación Primaria ${ }^{47}$ como de Secundaria. ${ }^{48}$

Así pues, los resultados de las investigaciones realizadas con manuales de historia muestran pocos cambios y muchas permanencias en el caso español. En Educación Primaria, frente al arcaico discurso españolista y cristiano, emerge una visión idealizada de Al-Ándalus y la supuesta convivencia pacífica de las tres culturas. Apenas se incide en la conquista de América por su carácter bélico y se prefiere aludir a las culturas prehispánicas. La convulsa historia de España en el siglo XX se resume en ideas clave (Guerra Civil, Transición, Constitución). Pero cuestiones polémicas, como la violencia de ambos bandos o represión de la dictadura, se pasan por alto.

En Educación Secundaria se percibe un relato que combina lo español ${ }^{49}$ y lo europeo. Pero la visión de Europa que contienen los manuales es una construcción identitaria ficticia, que salvo Mesopotamia y Egipto,

\footnotetext{
${ }^{45}$ Raimundo Cuesta, Clío en las aulas. La enseñanza de la Historia en España entre reformas, ilusiones y rutinas (Madrid: Akal, 1998); Francisco Javier Merchán, Enseñanza, examen y control: profesores y alumnos en clase de historia (Barcelona: Octaedro, 2005); Nicolás Martínez Valcárcel, Xosé Manuel Souto González y José Beltrán Llavador, «Los profesores de historia y la enseñanza de la historia en España. Una investigación a partir de los recuerdos de los alumnos», Enseñanza de las Ciencias Sociales, 5 (2006): 55-71; Pedro Miralles Martínez y Nicolás Martínez Valcárcel, «La fase de desarrollo de la clase de Historia en bachillerato", Revista Iberoamericana de Educación, 46 (1), (2008): 1-10.

${ }^{46}$ Dennis Shemilt, «Beauty and the philosopher: Empathy in history and classroom», en Learning history, eds. Alaric Dickinson, Peter Lee y Peter Rogers (Londres: Heinemann Educational Books, 1984), 39-84; Peter Lee y Rosalyn Asbhy, «Progression in Historical Understanding among Students ages 7-14», en Knowing, Teaching and Learning History. National and International Perspectives, eds. Peter N. Stearns, Peter Seixas y Sam Wineburg (Nueva York-Londres: New York University Press, 2000), 199-222.

47 Jorge Sáiz Serrano y Juan Carlos Colomer Rubio, «¿Se enseña pensamiento histórico en los libros de texto de Educación Primaria? Análisis de actividades de historia para alumnos de 10-12 años de edad», Clio. History and History Teaching, 40 (2014), consultado el 25 de junio de 2016, URL: http:// clio.rediris.es.

${ }^{48}$ Cosme Jesús Gómez Carrasco, «Pensamiento histórico y contenidos curriculares en los libros de texto. Un análisis exploratorio de la Edad Moderna en 2. ${ }^{\circ}$ de ESO», Ensayos, 29 (1), (2014): 131-158.

49 Juan Esteban Rodríguez Garrido, «Trato y maltrato de la Historia de España en los libros de la EGB y la ESO» (Tesis doctoral, Universidad Complutense de Madrid, 2011), 27-55.
} 
en tanto origen de la civilización, centra el discurso en rasgos supuestamente comunes de Europa desde la Antigüedad. Se obvia que griegos y romanos tenían parte esencial de sus dominios en Asia o África, o bien se da por válido el modelo feudal francés para todos los reinos cristianos de Europa. ${ }^{50}$ El tratamiento que recibe el período andalusí, aunque integrado en la historia peninsular, se desarrolla como un excurso en el devenir de un pasado cristiano, ${ }^{51}$ tan es así que al hablar de los musulmanes se sigue empleando la palabra «invasión», mientras que la visión de los visigodos alude a "llegada» o "entrada», dado que son monarcas cristianos y por tanto auténticos españoles. ${ }^{52}$ En cuanto a la Guerra Civil y la dictadura franquista, destaca el esfuerzo por afianzar los valores democráticos del alumnado. Aunque la visión sigue siendo excesivamente política y poco interesada en cuestiones de la vida cotidiana o traumas colectivos como la represión y el exilio.

El desfase entre las tendencias actuales sobre el modelo cognitivo de aprendizaje de la historia con la realidad del aula en España conlleva un conocimiento histórico débil. La escasa conexión de los avances historiográficos con decretos y manuales es otra dificultad para modernizar la enseñanza de la historia. Es necesario un aprendizaje basado en habilidades, que permitan al alumnado interpretar el pasado más allá del conocimiento factual, ${ }^{53}$ algo poco implantado aún en el sistema educativo español, pues las sucesivas leyes lo impiden.

A pesar de los cambios en el diseño de libros de texto, sobre todo desde la década de 1970, se percibe el retorno a una historia tradicional y nacionalista. ${ }^{54}$ También en otros países parece evidente ese proceso hacia una historia política de hechos, por encima de todo conocimiento histórico, en la cual prevalecen conceptos sobre procedimientos, relegando las habilidades históricas, el desarrollo cognitivo y la resolución de proble-

\footnotetext{
${ }^{50}$ López Facal, «Nacionalismos y europeísmos», 24-26.

${ }^{51}$ Jorge Sáiz Serrano, «Educación histórica y narrativa nacional» (Tesis doctoral, Universidad de Valencia, 2015), 251-285.

${ }^{52}$ Rafael Valls Montés, «La presencia del Islam en los actuales manuales españoles de historia», Íber. Didáctica de las ciencias sociales, geografía e historia, 20 (2011): 59-66.

${ }^{53}$ Isabel Barca, O pensamento histórico dos joves (Braga: Universidade do Minho, 2000); Stéphane Lévesque, Thinking Historically. Educating Students for the 21th Century (Toronto: Toronto University Press, 2008).

${ }^{54}$ López Facal, «La LOMCE», 17.
} 
mas. Así lo confirman trabajos sobre Inglaterra, ${ }^{55}$ Canadá, ${ }^{56}$ Australia ${ }^{57}$ o Portugal. ${ }^{58}$ Si bien es cierto que dichos países parten de unos sistemas educativos donde la enseñanza de la historia dejó atrás el modelo memorístico mucho antes, primando la selección de contenidos y su trabajo en profundidad.

\section{METODOLOGÍA, ANÁLISIS Y DISCUSIÓN DE RESULTADOS}

El objetivo principal de este trabajo es analizar la enseñanza de la historia en la ESO y la construcción de la narrativa regional, a través de los libros de texto y las actividades recogidas en los mismos. Para conseguirlo se plantean tres objetivos específicos:

1. Mostrar la tipología de contenidos (conceptuales, procedimentales y actitudinales) planteada lo largo de las tres últimas legislaciones educativas vigentes en España (LOGSE, LOE y LOMCE).

2. Observar la frecuencia de conceptos, etapas históricas y topónimos en las actividades de los libros de texto. A través de los mismos, analizar la construcción de una narrativa histórica regional y su influencia en la creación de identidades sociales y culturales.

3. Analizar las capacidades cognitivas que exigidas a los estudiantes de $1 .^{\circ}, 2 .^{\circ}$ y $4 .^{\circ}$ de la ESO, en los epígrafes dedicados a la historia y el patrimonio de la Región de Murcia.

El análisis de los datos se ha realizado combinando un enfoque cuantitativo y cualitativo, pues ambas metodologías en un mismo estudio resultan de gran utilidad para investigaciones de ciencias sociales, de cara a la profundización en los fenómenos educativos. Las principales inves-

${ }^{55}$ Hilary Cooper, History 3-11. Early Years and Primary. A guide for teachers (Londres: David Fulton Publishers, 2006).

${ }^{56}$ Ken Osborne, «Teaching history in schools: A Canadian debate», Journal of Curriculum Studies, 35 (5), (2003): 585-626.

57 Anna Clark, «Whose History? Teaching Australia's contested past», Journal of Curriculum Studies, 36 (5), (2004): 533-641.

${ }^{58}$ Glória Solé, «O manual escolar no ensino primário em Portugal: perspectiva histórica e análise do ensino da História a través deste recurso didáctico», Ensayos, 29 (1), (2004): 43-64. 
tigaciones sobre la educación histórica han insistido en la complementariedad de los estudios cuantitativos y cualitativos. ${ }^{59}$

El análisis cuantitativo se ha aplicado a través de la contabilización y porcentajes de una serie de variables. La finalidad ha sido desvelar la estructura subyacente en la enseñanza de la historia en la ESO, a través de las actividades de los manuales. A partir de los cuales se han analizado: tipologías de contenidos, bloques temáticos, etapas históricas, conceptos y topónimos. El análisis cualitativo complementa y explicita el anterior, con el fin de profundizar en la construcción de una identidad regional - en este caso murciana- a través de los manuales, por medio de la frecuencia de las variables aludidas.

La muestra de manuales de historia analizados es incidental, escogiéndose tres de las editoriales más importantes de España (Santillana, Vicens Vives, Oxford), con sus respectivas ediciones dedicadas a la Región de Murcia, a menudo cuadernillos que se anexan al manual estándar para todas las autonomías sin lengua propia. Se trata de nueve manuales: tres de $1 .^{\circ}$ de ESO,${ }^{60}$ tres de $2 .{ }^{\circ}$ de $\mathrm{ESO}^{61}$ y tres de $4 .{ }^{\circ}$ de ESO. ${ }^{62} \mathrm{Si}$ bien la LOMCE aún sólo se ha implantado en los cursos impares de ESO, estando prevista para el curso próximo (2016/17) que se amplíe a los pares. Así pues cabe subrayar que es una etapa de transición, con LOE y LOMCE aún activas en ESO. En concreto, para este trabajo exploratorio se han localizado manuales de las

\footnotetext{
59 Joaquim Prats, «Hacia una definición de la investigación en Didáctica de las Ciencias Sociales», Enseñanza de las Ciencias Sociales, 1 (2002): 81-89; Keith Barton, «Applied research: Educational research as a way of seeing», en The professional teaching of history: UK and Dutch perspectives, eds. Allan McCully, Garry Mills y Carla van Boxtel (Coleraine: History Teacher Education Network, 2012), 1-15.

${ }^{60}$ Abel Albet, et al., 1 Ciencias Sociales, Geografía e Historia. Limes, Región de Murcia (Barcelona: Vicens Vives, 2003); Celia Carrasco Márquez et al., Ciencias Sociales. Geografía e Historia, 1. ${ }^{\circ}$ ESO. Región de Murcia (Madrid: Oxford, 2011); María Ángeles Fernández de Bartolomé, et al., 1 ESO. Geografía e Historia, Región de Murcia (Madrid: Santillana, 2015). Estos libros se designan I, II y III en las tablas, siguiendo el orden cronológico (LOGSE, LOE y LOMCE).

${ }^{61}$ Margarita García Sebastián, et al., 2 Ciencias Sociales, Geografía e Historia. Limes, Región de Murcia (Barcelona: Vicens Vives, 2005); Abel Albet, et al., Ciencias Sociales, Geografía e Historia. Nuevo Demos 2 Educación Secundaria (Barcelona: Vicens Vives, 2013); Margarita García Sebastián, Cristina Gatell Arimont y Sergio Riesco Roche, Geografía e Historia. 2.1 Historia, Región de Murcia (Barcelona: Vicens Vives, 2016). Estos libros se designan IV, V y VI en las tablas, siguiendo el orden cronológico (LOGSE, LOE y LOMCE).

${ }^{62}$ Margarita García Sebastián, et al., 4 Ciencias Sociales, Historia. Limes, Región de Murcia (Barcelona: Vicens Vives, 2004); María Isabel Fernández Armijo, et al., Historia $4 .^{\circ}$ ESO, Región de Murcia (Madrid: Oxford, 2012); Rosa Marín, et al., Historia 4 ESO, Región de Murcia (Madrid: Santillana, 2013). Estos libros se designan VII, VIII y IX en las tablas, siguiendo el orden cronológico (LOGSE, LOE y LOMCE).
} 
tres legislaciones (LOGSE, ${ }^{63} \mathrm{LOE}^{64} \mathrm{y} \mathrm{LOMCE}^{65}$ ) de $1 .^{\circ}$ y $2{ }^{\circ}$ de ESO, pero no de $4 .^{\circ}$. Además, con la nueva legislación la historia pasará a ser enseñada en todos los cursos de ESO, cuando antes siempre había uno (3..$^{\circ}$ que se dedicaba solamente a la Geografía, pero que a partir de ahora tratará contenidos de Historia Moderna, concretamente los siglos XVI y XVII, período que antes venían estudiándose en 2. ${ }^{\circ}$ de ESO, junto a la Edad Media.

El análisis llevado a cabo se detiene en las actividades que los nueve manuales seleccionados plantean a lo largo y al final de cada tema o epígrafe dedicado a la actual Región de Murcia, desde la Prehistoria hasta la actualidad. En total, son 412 actividades. Sabiendo que el manual es el principal recurso docente, aunque todas esas actividades no sean forzosamente respondidas, su interés en innegable como vehículo de transmisión del saber, aunque sea esencialmente memorístico.

Las variables seleccionadas sirven para clasificar la información más relevante, a pesar del escaso espacio que las distintas editoriales dedican a la historia de la actual Región de Murcia. Pues pese a su casi nula presencia en decretos y, por ende, manuales, su relevancia para enseñar el rigor científico de la historia, su utilidad para la sociedad y para formar a ciudadanos críticos está fuera de duda. Es decir, poner datos acerca de qué hechos, datos, fechas, coyunturas y lugares del territorio murciano aparecen más. Al contrario que a nivel universal o estatal, se ha optado por no estudiar personajes emblemáticos, que aparecen muy poco aludidos en las actividades, así que su análisis sería poco representativo. Con todo, se debe señalar que Tudmir, el Rey Lobo, Alfonso X el Sabio son los emblemas del período medieval, en tanto que Salzillo y Floridablanca lo son del moderno. En la Antigüedad y época contemporánea apenas hay personajes de referencia, de modo que la identidad del espacio murciano se configura a partir del reino medieval y sus principales eventos

${ }^{63}$ Ley Orgánica 1/1990, de 3 de octubre, de Ordenación General del Sistema Educativo (LOGSE). La Comunidad Autónoma de la Región de Murcia asumió del Estado la competencia en materia de enseñanza no universitaria por el Real Decreto 938/1999, de 4 de junio.

${ }^{64}$ Ley Orgánica 2/2006, de 3 de mayo, de Educación (LOE). Desarrollada a nivel autonómico en el Decreto 291/2007 del Boletín Oficial de la Región de Murcia (BORM), del 14 de septiembre, por el que se establece el currículo de la Educación Secundaria Obligatoria en la Comunidad Autónoma de la Región de Murcia.

${ }^{65}$ Ley Orgánica 8/2013, de 9 de diciembre, para la Mejora de la Calidad Educativa (LOMCE). Desarrollada a nivel autonómico en el Decreto 220/2015 del BORM, de 2 de septiembre, por el que se establece el currículo de la Educación Secundaria Obligatoria en la Comunidad Autónoma de la Región de Murcia. 
políticos, bélicos y artísticos. Lo económico y social queda relegado a un segundo plano, frente a la información factual de tipo político y cultural (guerras, reinados, fechas, bienes monumentales).

La cantidad de temas o epígrafes dedicados a la historia de la actual Comunidad Autónoma de la Región de Murcia es ínfima, tal y como se observa en la tabla 1. Ello deriva del exiguo $10 \%$ de contenidos regionales que prevén las legislaciones educativas. Además, el hecho de verse relegados al final de la parte de historia universal y de España conlleva una posición residual, sin apenas tiempo para ser impartidos o tratados. Son un complemento en manuales de la ESO que, con los decretos LOGSE y LOE, debían abordar tanto la geografía como la historia en el área de Conocimiento del medio natural, social y cultural. Un despropósito inabarcable por la cantidad y complejidad de contenidos. No obstante, interesa saber, a partir del muestreo realizado, qué tipo de contenidos y actividades de índole regional recogen algunas de las principales editoriales del Estado español.

El análisis de las actividades sobre patrimonio en manuales de Educación Primaria y ESO ha dado como resultado diversas publicaciones, por parte del grupo de investigación EDIPATRI de la Universidad de Huelva. En ellas se constata el uso academicista de las imágenes y actividades de los manuales en diversas autonomías, con tareas que presentan una baja complejidad. ${ }^{66}$ A pesar de la cortedad de la muestra empleada para la Región de Murcia, centrada no en imágenes, sino en actividades tanto de historia como de patrimonio, puede constatarse lo mismo, como se verá a continuación.

Para la Región de Murcia, existe un reciente artículo de Sánchez Ibáñez y Martínez Nieto sobre las imágenes en manuales de $2 .^{\circ}$ y $4 .^{\circ}$ de la ESO, ${ }^{67}$ vigentes con el Decreto del BORM 291/2007(LOE). Un trabajo que incide en el carácter complementario de las ilustraciones y actividades ligadas al patrimonio autonómico, que promueven una visión identitaria, pero escasamente significativa en tanto conceptual y decorativa de las sucesivas etapas históricas.

\footnotetext{
${ }^{66}$ Jesús Estepa Giménez, et al., «Análisis del patrimonio presente en los libros de texto: obstáculos, dificultades y propuestas», Revista de Educación, 355 (2011): 573-589; Mario Ferreras-Listán y Roque Jiménez Pérez, «¿Cómo se conceptualiza el patrimonio en los libros de texto de Educación Primaria?», Revista de Educación, 361 (2013): 591-618.

${ }^{67}$ Raquel Sánchez Ibáñez y Alejandro Martínez Nieto, «Patrimonio e identidad de la Región de Murcia: una aproximación a través del currículo y los libros de texto de Ciencias Sociales de Secundaria», Clío. History and History Teaching, 41 (2015), consultado el 13 de mayo de 2016, URL: http://clio.rediris.es
} 
En la tabla 1 se detalla el número de temas dedicados a historia universal, de España y de la Región de Murcia. Esta última aparece sólo en 15 temas de los nueve manuales analizados, un 14,28\% de los contenidos. Normalmente un único tema de historia regional (máximo 2 o 3 en casos puntuales) en manuales que abarcan de 10 a 20 aproximadamente. Más de la mitad son temas de historia universal, de corte eurocéntrico, salvo para las primeras civilizaciones (Mesopotamia y Egipto) y los procesos colonizadores. Los temas de historia de España suponen poco más de un tercio de la muestra consultada. Solamente dos manuales de $2{ }^{\circ} \mathrm{de}$ la ESO (LOE y LOMCE) dedican más espacio a la historia nacional que a la universal.

Tabla 1. Temas en los manuales de la ESO de historia de la Región de Murcia

\begin{tabular}{|c|c|c|c|}
\hline MANUAL & $\begin{array}{c}\text { HISTORIA } \\
\text { UNIVERSAL }\end{array}$ & $\begin{array}{c}\text { HISTORIA } \\
\text { DE ESPAÑA }\end{array}$ & $\begin{array}{c}\text { HISTORIA DE } \\
\text { LA REGIÓN } \\
\text { DE MURCIA }\end{array}$ \\
\hline I & 6 & 1 & 1 \\
\hline II & 4 & 2 & 1 \\
\hline III & 12 & 6 & 3 \\
\hline IV & 5 & 3 & 1 \\
\hline V & 4 & 6 & 2 \\
\hline VI & 3 & 5 & 3 \\
\hline VII & 10 & 7 & 2 \\
\hline VIII & 4 & 4 & 1 \\
\hline IX & 5 & 3 & 15 \\
\hline Total (105) & 53 & 37 & \\
\hline
\end{tabular}

Fuente: Elaboración propia.

El tipo de contenidos que se demandan al estudiante de la ESO en las actividades de los nueve manuales analizados es abrumadoramente conceptual. Es decir, que señale fechas, nombres, datos o eventos concretos, a partir del texto de la misma página o la inmediatamente previa a la actividad. En las actividades de repaso, al final del tema, se repiten a menudo las mismas preguntas, apenas modificadas, ya expuestas a lo largo del bloque dedicado a la historia de la actual Región de Murcia. La tabla 2 muestra que de las 412 actividades analizadas 329 son de tipo 
conceptual, lo que supone un $79,85 \%$ del total. Por tanto, las editoriales siguen ancladas en un modelo educativo memorístico y enciclopédico, que prima el saber a secas, sin razonamiento, empatía, retos o interrogantes. Nada de pensar históricamente, ni abordar causalidad, cambios o permanencias, fenómenos del tiempo largo braudeliano, nada de contenidos de segundo orden o metahistóricos. ${ }^{68} \mathrm{Y}$ no se aprecia evolución desde los manuales de LOGSE a los ya vigentes de LOMCE, pasando por la LOE, sino una tendencia hegemónica inalterable.

Las actividades de tipo procedimental: saber hacer, explicar, razonar a partir de un mapa, texto, línea del tiempo o imagen son sólo $82(19,9 \%)$. En tanto que una sola actividad demanda tarea de tipo actitudinal, vinculada a la conservación y puesta en valor del patrimonio, o sea un $0,24 \%$ de la muestra. Si el saber hacer queda reducido a menos de una quinta parte de las actividades, el saber ser apenas es testimonial. Los cambios legislativos y pedagógicos producidos desde la década de 1990 no han influenciado los manuales vigentes, predominando la idea de impartir una enorme cantidad de temas, esto es períodos históricos, en un único curso, por ende en un único manual.

Tabla 2. Tipo de contenido en las actividades de los manuales de la ESO de historia de la Región de Murcia

\begin{tabular}{|c|c|c|c|}
\hline MANUAL & CONCEPTUAL & PROCEDIMENTAL & ACTITUDINAL \\
\hline I & 38 & 5 & 0 \\
\hline II & 30 & 5 & 0 \\
\hline III & 19 & 5 & 0 \\
\hline IV & 19 & 4 & 0 \\
\hline V & 88 & 22 & 1 \\
\hline VI & 18 & 5 & 0 \\
\hline VII & 46 & 9 & 0 \\
\hline VIII & 44 & 18 & 0 \\
\hline IX & 27 & 82 & 1 \\
\hline Total (412) & 329 & & 0 \\
\hline
\end{tabular}

Fuente: Elaboración propia.

68 Sam Wineburg, Historical Thinking and Other Unnaturals Acts: Charting the Future of Teaching the Past (Philadelphia: Temple University Press, 2001). 
El tipo de información que demandan las actividades de historia de los manuales de la ESO ha sido dividido para este análisis en cuatro grandes bloques: política, sociedad, economía y arte, tal y como puede apreciarse en la tabla 3. En este caso el número de actividades se reduce levemente respecto al total referido (412) pasando a 401, pues las 11 restantes aluden a dos o más temáticas en una sola pregunta o tarea, por ejemplo a política, economía y sociedad. La política se refiere a información sobre fronteras, batallas, regímenes o instituciones, a menudo ligados a fechas o cronologías. Es la información factual por excelencia, la madre, por así decirlo, de la enseñanza positivista y decimonónica de la historia, ligada a lo ya señalado sobre actividades ante todo conceptuales. El predominio de actividades de esta índole es abrumador en los nueve manuales, con $157(39,15 \%)$.

La sociedad se vincula a actividades sobre población, migraciones, clases, estamentos o grupos sociales. Su papel es residual, siendo el bloque con menos actividades: 51 (12,71\%). La economía se refiere a sectores productivos predominantes en cada época (agricultura, ganadería, comercio, industria, servicios), con un peso levemente superior a la sociedad: 77 actividades $(19,2 \%)$.

La sorpresa viene de la mano de las actividades que inciden en cuestiones artísticas o patrimoniales: $116(28,92 \%)$. El peso de lo cultural tiene que ver con yacimientos arqueológicos, monumentos y obras de arte emblemáticas de cada período histórico y de cada civilización que habitó la actual Región de Murcia. Es, junto a la demarcación territorial (reino/ región), el gran forjador de identidad. El que legitima un legado común a conservar y divulgar para conocer lo más valioso. Ahora bien, como era de esperar los monumentos u obras son esencialmente arquitectónicos, escultóricos y pictóricos, salvo en la Prehistoria y Edad Antigua donde la cultura material (cerámica, tumbas) juega un papel decisivo.

Junto a los grandes emblemas monumentales de la Región de Murcia, que van del Gótico al Barroco, aparecen en los manuales más recientes yacimientos o museos puestos en valor en fechas cercanas. Así pues, además de edificios religiosos (catedral de Murcia, colegiata de Lorca) han cobrado interés el yacimiento argárico de La Bastida (Totana) y el teatro romano de Cartagena. Se habla de un estilo o escuela gótica, renacentista, barroca (que incluye los siglos XVII y XVIII) y modernista en la 
Región de Murcia, pues al hablar de arte desaparece el vocablo «reino». Pero en época andalusí, los principales edificios o restos no han sido incorporados al texto y por ende a las actividades de él emanadas, algo que sorprende dada la relevancia del poblado de Siyasa (Cieza), la red de regadío de la huerta de Murcia o el castillo de Monteagudo. Incluso en la editorial Vicens Vives, que de las tres analizadas es la más completa respecto a cuestiones regionales, se perpetúan errores en manuales tanto de la LOGSE como de la LOE y la LOMCE: señalar los baños de Alhama como árabes, cuando son termas romanas; considerar la rueda de Alcantarilla como símbolo de legado islámico, si bien data del siglo XV (época bajomedieval cristiana). Sin embargo, lo más relevante es dejar el patrimonio andalusí al margen de esas escuelas artísticas locales, siendo un paréntesis en la evolución del reino, provincia y autonomía cristiana. Este carácter exógeno de lo islámico se observa también a escala estatal, tal y como han señalado Valls Montés o Sáiz Serrano. ${ }^{69}$

Tabla 3. Información demandada en las actividades de los manuales de ESO de historia de la Región de Murcia

\begin{tabular}{|c|c|c|c|c|}
\hline MANUAL & POLÍTICA & SOCIEDAD & ECONOMÍA & ARTE \\
\hline I & 16 & 4 & 5 & 18 \\
\hline II & 6 & 2 & 8 & 15 \\
\hline III & 9 & 1 & 2 & 12 \\
\hline IV & 16 & 2 & 1 & 6 \\
\hline V & 46 & 25 & 8 & 30 \\
\hline VI & 15 & 0 & 0 & 8 \\
\hline VII & 19 & 6 & 17 & 13 \\
\hline VIII & 24 & 5 & 12 & 0 \\
\hline IX & 6 & 6 & 24 & 116 \\
\hline Total (401) & 157 & 51 & 77 & \\
\hline
\end{tabular}

Fuente: Elaboración propia.

Las cinco grandes etapas históricas vienen detalladas en la tabla 4. En ella se observa el predominio de las actividades referentes a la Edad Media, con 110 (26,69\%). Es la etapa donde se forjan las fronteras del rei-

69 Valls Montés, «La presencia del Islam», 59-66; Sáiz Serrano, «Educación histórica», 251-160. 
no, casi inalterables desde 1243 hasta 1833. Los manuales de la ESO dan mayor relevancia al Medievo, coincidiendo con los historiadores en que esa etapa es la clave en tanto germen de la identidad territorial, histórica y cultural de los murcianos.

A escasa diferencia se queda la Edad Antigua, con 103 actividades (25\%). La importancia de la cultura íbera y sobre todo romana explican esta privilegiada situación; además, se da la inclusión de los visigodos y bizantinos en un período que la historiografía tradicional europea y española siempre había vinculado a la alta Edad Media. En cualquier caso, estos dos pueblos tienen una presencia testimonial, como puede comprobarse en la tabla 5.

Por su parte, la Edad Moderna aglutina 95 actividades (23,05\%). En ella se incluyen los siglos XVI, XVII y XVIII. Este último, a pesar de que en los manuales LOE se estudiaba junto a la etapa contemporánea (siglos XIX y $\mathrm{xx}$ ), alterando al académica división del estudio de la historia para situar el Siglo de las Luces como preludio de la época actual.

Las Edad Contemporánea y la Prehistoria muestran un perfil más bajo, con 56 y 48 actividades cada una, lo cual supone un 13,59\% y $11,65 \%$ respectivamente. En este sentido llama la atención que la etapa histórica más prolongada, que abarca desde la hominización hasta la aparición de la escritura deje tan escaso rastro, siendo la que menos actividades ocupa. Máxime dada la relevancia de los yacimientos de la actual Región de Murcia, que es una de las pocas zonas de Europa con tres asentamientos del hombre de Neanderthal, sin olvidar la abundancia de abrigos con pinturas rupestres levantinas (el único patrimonio material de la Humanidad en la Región) o el esplendor de la cultura argárica, en la Edad del Bronce.

Por otro lado, la época contemporánea muestra la evolución de la provincia murciana durante los siglos XIX y XX, con apenas actividades que aludan al siglo XxI. Es una sucesión de regímenes o reinados en los que se sintetiza el papel de Murcia en los acontecimientos más relevantes de la compleja historia de España de este período: Guerra de la Independencia, liberalismo, industrialización, Guerra Civil, franquismo y democracia. La actual Comunidad Autónoma es un apéndice de lo que sucede en los centros de poder (casi siempre lejanos), salvo en coyunturas ex- 
cepcionales como el Cantón de Cartagena, que supone un protagonismo fugaz (1873-1874) durante la también fugaz I República.

Tabla 4. Las etapas históricas en las actividades de los manuales de la ESO de historia de la Región de Murcia

\begin{tabular}{|c|c|c|c|c|c|}
\hline MANUAL & PREHISTORIA & $\begin{array}{c}\text { EDAD } \\
\text { ANTIGUA }\end{array}$ & $\begin{array}{c}\text { EDAD } \\
\text { MEDIA }\end{array}$ & $\begin{array}{c}\text { EDAD } \\
\text { MODERNA }\end{array}$ & $\begin{array}{c}\text { EDAD } \\
\text { CONTEMPORÁNEA }\end{array}$ \\
\hline I & 16 & 25 & 0 & 0 & 0 \\
\hline II & 25 & 61 & 0 & 0 & 0 \\
\hline III & 7 & 17 & 0 & 0 & 0 \\
\hline IV & 0 & 0 & 30 & 0 & 0 \\
\hline V & 0 & 0 & 68 & 55 & 0 \\
\hline VI & 0 & 0 & 12 & 0 & 16 \\
\hline VII & 0 & 0 & 0 & 25 & 20 \\
\hline VIII & 0 & 0 & 0 & 15 & 30 \\
\hline IX & 0 & 0 & 0 & 0 & 56 \\
\hline Total (412) & 48 & 103 & 110 & 95 & 0 \\
\hline
\end{tabular}

Fuente: Elaboración propia.

La tabla 5 complementa la anterior, al desglosar los conceptos más comunes dentro de cada etapa histórica. En 1. ' de ESO destacan «Roma» (35) e «Íberos» (22), es decir la época antigua tiene preponderancia frente a la prehistórica. En 2. ${ }^{\circ}$ de ESO abunda la alusión a la época medieval cristiana (66). Si se añade el arte de ese período - el Gótico (15), especialmente la catedral de Murcia- nos da 81 actividades sobre el período del reino cristiano de Murcia, el concepto más frecuente de los nueve manuales analizados. Ello alude a la relevancia del Medievo, pero un Medievo cristiano, pues lo andalusí, sin ser escaso, se refleja en bastantes actividades menos (24).

La Edad Moderna, como se ha visto en la tabla 4, queda en una posición intermedia y a caballo entre dos cursos $\left(2{ }^{\circ}\right.$ y $4 .^{\circ}$ de ESO). La frecuencia más destacada para el período contemporáneo, es decir en manuales de $4 .^{\circ}$ de ESO, se refiere al siglo XX, con 57 actividades, casi el doble que el siglo XIX, mientras que el siglo XXI apenas tiene presencia, ni siquiera como preguntas que aludan a la actualidad. La Guerra Civil, la dictadura franquista, la transición democrática y el surgimiento de la entidad auto- 
nómica (1982) parecen culminar la historia contemporánea. Apenas hay actividades sobre arte contemporáneo, frente a la importancia relativa otorgada al Gótico, el Renacimiento y el Barroco. La falta de perspectiva impide analizar cuestiones actuales, a pesar de que los enlaces a las web de las editoriales podrían solventar esa cuestión.

Tabla 5. Conceptos más frecuentes en las actividades de los manuales de la ESO de historia de la Región de Murcia

\begin{tabular}{|c|c|}
\hline ETAPA HISTÓRICA Y CONCEPTOS & $\begin{array}{c}\text { FRECUENCIA EN MANUALES } \\
\text { DE LA ESO }\end{array}$ \\
\hline \multicolumn{2}{|l|}{ PREHISTORIA } \\
\hline Paleolítico & 8 \\
\hline Neolítico & 13 \\
\hline Edad de los Metales & 13 \\
\hline \multicolumn{2}{|l|}{ HISTORIA ANTIGUA } \\
\hline Íberos & 22 \\
\hline Cartagineses & 9 \\
\hline Roma/romanos & 35 \\
\hline Visigodos & 4 \\
\hline Bizantinos & 5 \\
\hline \multicolumn{2}{|l|}{$E D A D$ MEDIA } \\
\hline Al Ándalus & 24 \\
\hline Período cristiano & 66 \\
\hline Gótico & 15 \\
\hline \multicolumn{2}{|l|}{ EDAD MODERNA } \\
\hline Siglo XVI & 22 \\
\hline Renacimiento & 6 \\
\hline Siglo XVII & 19 \\
\hline Siglo XVIII & 24 \\
\hline Barroco & 5 \\
\hline \multicolumn{2}{|l|}{ EDAD CONTEMPORÁNEA } \\
\hline Siglo XIX & 39 \\
\hline Siglo $\mathrm{xx}$ & 57 \\
\hline Siglo XXI & 3 \\
\hline
\end{tabular}

Fuente: Elaboración propia. 
Los topónimos desglosados en la tabla 6 complementan el análisis, esencialmente temático y cronológico. De las 237 alusiones a lugares casi la mitad se refieren a "Región de Murcia», concretamente 101 (42,61\%). A mucha distancia le sigue "Reino de Murcia», con 54 (22,78\%). El topónimo regional se emplea en todos los manuales, desde la Prehistoria hasta la actualidad, ello implica un evidente presentismo, con afán de perpetuar una supuesta identidad y fronteras comunes desde la noche de los tiempos. Esto no difiere de las historias nacionales o de otras autonomías españolas. El topónimo «Reino de Murcia»se emplea con mayor corrección, durante el Medievo y la Edad Moderna, si bien en los apartados dedicados al arte las actividades aluden a Región de Murcia o «tierras murcianas» o «territorio murciano».

Respecto a los municipios, sólo los tres más importantes de la Región tienen una relevancia destacable: "Murcia», "Cartagena» y "Lorca». La capital autonómica aparece en 40 actividades $(16,87 \%)$, de hecho su protagonismo en la historia regional es indiscutible desde el siglo IX hasta la actualidad, dado el marcado centralismo político y cultural, así como sus épocas de esplendor en las segundas taifas andalusíes, el Renacimiento y el Barroco dieciochesco. Le sigue "Cartagena» con 15 actividades $(6,32 \%)$, relativas a los acontecimientos de primer orden, a nivel nacional e incluso universal, transcurridos allí durante la Antigüedad y época contemporánea (colonia cartaginesa, conquista romana, cantón), no en vano es la ciudad más antigua de la Región. «Lorca», en menor medida con 9 actividades $(3,79 \%)$, por su condición de bastión castellano en la frontera de Granada y su legado artístico de los siglos XVI al XVIII. Las demás localidades sólo aparecen en una, dos o tres actividades.

Por último, hay que señalar que la perspectiva regionalista de la historia impide que los manuales recojan, salvo en algún mapa, alusión a localidades -incluidas desde 1833 en las provincias de Alicante y Albacete- de gran relevancia durante el período medieval y moderno en el reino de Murcia: Orihuela, Villena, Chinchilla, Albacete, Hellín, Almansa. De igual modo, los personajes, monumentos y obras de arte más relevantes de las mismas no constan en las actividades de los manuales destinados a la Región de Murcia, cuando sin ellos no se puede entender la Edad Media y el Antiguo Régimen en el reino murciano: por ejemplo, el ilustrado hellinense Macanaz. Las fronteras provinciales, que no llegan 
a dos siglos de antigüedad, y las autonómicas, de apenas tres décadas, se imponen sobre un reino (Murcia) o una diócesis (Cartagena) vigentes durante siete siglos.

Tabla 6. Topónimos en las actividades de los manuales de la ESO de historia de la Región de Murcia

\begin{tabular}{|c|c|}
\hline TOPÓNIMO & $\begin{array}{c}\text { FRECUENCIA EN MANUALES } \\
\text { DE LA ESO }\end{array}$ \\
\hline Región de Murcia & 101 \\
\hline Reino de Murcia & 54 \\
\hline Murcia (ciudad) & 40 \\
\hline Cartagena & 15 \\
\hline Lorca & 9 \\
\hline Yecla & 3 \\
\hline La Manga del Mar Menor & 3 \\
\hline Mula & 2 \\
\hline Totana & 2 \\
\hline Águilas & 2 \\
\hline Mazarrón & 2 \\
\hline Ricote & 2 \\
\hline Fortuna & 1 \\
\hline La Alberca de las Torres & 1 \\
\hline Total & 237 \\
\hline
\end{tabular}

Fuente: Elaboración propia.

\section{CONCLUSIONES}

La enseñanza de la historia surge en España, al igual que en el resto de Europa, en el siglo XIX y se consolida a fines de dicha centuria e inicios de la siguiente, de la mano del positivismo. La modernización de la misma se ve frenada por la dictadura franquista, verdadero punto de inflexión, que paraliza la incipiente escuela pública y laica, promovida por la II República. A partir de la década de 1970 se inician profundos cambios, motivados por la recuperación de la democracia. Aunque habrá que esperar aún dos décadas para una definitiva modernización curricular. 
En los últimos años, la introducción de la enseñanza por competencias parecía animar un cambio de paradigma; sin embargo, se ha visto truncado por las inercias docentes, apegadas a un modelo de historia factual vigente casi dos siglos, así como por la involución conservadora en las leyes educativas. Entre los retos principales sigue presente la necesidad de desterrar una enseñanza de la historia basada sólo en conceptos y memorización.

El libro de texto permanece como el material didáctico más utilizado en España tanto en Educación Primaria como Secundaria. ${ }^{70} \mathrm{El}$ análisis y estudio de los manuales escolares de historia ha cobrado gran relevancia, en especial desde la década de 1990. La presencia islámica durante varios siglos y, sobre todo, la condición de primer imperio colonial, así como su decadencia, la frágil construcción de un Estado liberal en el siglo XIX, y las dos dictaduras del siglo xx marcan el devenir histórico del territorio que hoy ocupa el Estado español, y así es reflejado en los manuales. El afán nacionalista se complementa, a partir del último tercio del siglo $\mathrm{xx}$, con la insistencia en una supuesta identidad común europea, especialmente visible en la enseñanza secundaria, mientras que en primaria predomina lo nacional. La historia ya no se construye tanto en función de las luchas contra musulmanes, franceses o ingleses, si bien la visión eurocéntrica también es una construcción interesada y artificial.

Con la LOMCE se refuerza aún más el Estado-nación que, como recuerda Álvarez Junco, no deja de ser un invento, un dios útil de las élites burguesas, forjador de identidades y ciudadanos obedientes al poder y leales a unos símbolos y una patria que defender frente al enemigo exterior o el separatista endógeno. ${ }^{71}$ Para regiones pequeñas sin una tradición reivindicativa, como la murciana, la recentralización de los contenidos históricos supone retroceder en lo poco que se había avanzado en aprecio por lo local, comarcal y autonómico. La entidad territorial puede decirse que está consolidada, pero mientras no se conozca mejor no dejará de ser un mero entramado burocrático.

Por tanto es necesario dotar de unos contenidos mínimos sobre Geografía, Historia e Historia del Arte de la Región de Murcia a futu-

${ }^{70}$ Valls Montés, Historiografía escolar española, 38-72; Prats, «Criterios para la elección», 7-13.

71 Álvarez Junco, Dioses útiles, 39-52. 
ros docentes de Primaria y Secundaria. Sólo así pueden superarse los estrechos márgenes de decretos y manuales, además de los exámenes emanados de ellos, que reducen su protagonismo a la mínima expresión. La Región de Murcia debería hacer de su diversidad patrimonial uno de sus signos de identidad y motores de desarrollo, como el resto de España, no propugnando por ello ningún hecho diferencial. Existen acontecimientos, personajes y monumentos que tienen relevancia fuera de las reducidas fronteras regionales. La historia del actual territorio autonómico también ayudaría a entender la vida cotidiana y la historia reciente. Incluso los espacios degradados o desaparecidos ofrecen un recurso didáctico de primer nivel, clave para: conciencia y movilización ciudadana; rehabilitación y musealización; entender procesos de cambio y continuidad.

La única forma de sacar la historia regional de lugares de memoria como museos y archivos, además de publicaciones para eruditos, es que los docentes de niveles educativos iniciales tengan una sólida formación sobre el territorio circundante, sus valores y problemas. La función de dichos docentes no es que el alumnado memorice fechas, batallas y personajes, sino que entienda el valor que un blasón, una ermita o una canción tradicional tiene, por humilde que sea. Lo que se desconoce se infravalora. Los investigadores y didactas de la historia tienen que acercar la historia regional a la sociedad, divulgarla, sin que ello suponga considerar que lo autóctono es superior a lo foráneo, pero tampoco inferior.

Las últimas tendencias historiográficas (historia cultural, microhistoria) no han llegado a la didáctica de la historia ni, por supuesto, a los manuales escolares. Los historiadores deben colaborar con docentes en crear manuales más actualizados e interesantes para el alumno, que le ofrezcan retos, preguntas, que estimulen su curiosidad y no sólo una letanía de fechas, nombres y conceptos, necesarios pero que por sí solos aburren y no dejan entrever la utilidad de la historia. No en vano los manuales son la principal (y a menudo única) narrativa histórica que muchos ciudadanos leerán en su vida, así que de su calidad y rigor depende la valoración que la sociedad haga de su propia identidad, patrimonio y entorno. Si el problema es conocido para cuestiones relativas a la enseñanza de la historia universal y nacional, en el ámbito regional 
la situación es aún más grave, dada la marginación de esos contenidos y el consiguiente desaprovechamiento de su enorme potencial didáctico. Por tanto, el caso murciano permite detectar carencias y extrapolar propuestas útiles para el resto de autonomías, especialmente aquellas no reconocidas como nacionalidades históricas en la Constitución de 1978.

El predominio de actividades de tipo conceptual, a lo largo y al final de los sucesivos temas de los nueve manuales de la ESO analizados es abrumador. Las actividades procedimentales son marginales y las actitudinales apenas existen. Así pues hablar de educación cívica o en valores se convierte en algo utópico. La escasísima presencia de cuestiones que demanden al alumno reelaboración de lo aprendido por sí mismos, procesos de causalidad o extrapolar a otros lugares o épocas, indica una nula educación por competencias, dado que el saber hacer apenas tiene cabida. De modo que si a nivel de historia de España y universal el panorama es poco alentador, a nivel de historia regional es nefasto. La culpa no reside sólo en las editoriales, sino que la raíz del problema está en los currículos enciclopédicos, que apenas responden a las nuevas corrientes historiográficas y pedagógicas. Siguen anclados, tanto las leyes como los libros de texto, en una enseñanza tradicional, memorística y de corte político. Una sucesión de civilizaciones, imperios y gobiernos, que en los escasos temas o epígrafes dedicados a la autonomía de turno se complementan con actividades de tipo cultural: yacimientos y monumentos representativos de cada período.

Los cambios legislativos y mejoras en el diseño de manuales han supuesto, a menudo, perpetuar las mismas imágenes, mapas y preguntas, aunque cambie el decreto curricular. Aún más grave es el escaso tiempo que el docente puede dedicar a cuestiones de historia y patrimonio regional o local, dada la enorme cantidad de temario a impartir, ligado a contenidos universales y españoles. Con un predominio abrumador de la lección magistral, el manual y el examen escrito (esencialmente conceptual) es improbable plantear actividades ligadas a la historia o el legado cultural del entorno próximo. Ello requeriría seleccionar unos pocos temas para abordarlos en profundidad mediante estrategias de indagación y trabajo cooperativo, algo aún harto infrecuente en Educación Primaria y más aún en Secundaria. 


\section{Nota sobre los autores:}

Raimundo A. Rodríguez PÉRez es Licenciado en Historia, Doctor en Historia Moderna y Profesor Contratado Doctor de Didáctica de las Ciencias Sociales en la Universidad de Murcia (acreditado como Profesor Titular desde 2015). Ha sido becario predoctoral del Ministerio de Educación y de la Fundación Séneca. Actualmente es coordinador del Grado en Educación Primaria de la Facultad de Educación de la Universidad de Murcia. Imparte docencia en dicho grado y en el Máster de Investigación e Innovación en Educación Infantil y Primaria. Sus líneas de investigación se centran en la formación docente, la evaluación y las metodologías didácticas en Educación Primaria y Secundaria. Entre su más de medio centenar de publicaciones destacan tres libros como coeditor: Investigación e innovación en Educación Infantil (2014); Innovación y enseñanza en Educación Primaria (2015); La Edad Moderna en Educación Secundaria. Experiencias de investigación (2016). De los artículos cabe subrayar: «La enseñanza de la Historia en Educación Primaria y la construcción de una narrativa nacional. Un estudio sobre exámenes y libros de texto en España», Perfiles Educativos, 150 (2015): 20-38, y «La Historia Social de la familia en España y su repercusión en la Didáctica de las Ciencias Sociales», Tempo e Argumento, 6 (11), (2014): 54-77.

MARÍA DEL MAR Simón García es Licenciada en Humanidades y Diplomada de Magisterio de Educación Primaria por la Universidad de Castilla-La Mancha. Fue becaria de investigación (FPI) de la Universidad de Castilla-La Mancha y Profesora Asociada de Historia Moderna en la Facultad de Ciencias de la Educación y Humanidades de Cuenca por la misma universidad. En la actualidad es Profesora Asociada de Didáctica de las Ciencias Sociales de la Facultad de Educación de la Universidad de Murcia y profesora de Educación para Personas Adultas en el Aula de Chinchilla de Montearagón (adscrita al Centro de Educación de Personas Adultas Los Llanos de Albacete). Sus líneas de investigación se centran en la Educación de Personas Adultas, el desarrollo de materiales y recursos didácticos para la enseñanza de las ciencias sociales y en la formación del profesorado. De sus publicaciones destaca el libro Familia, propiedad y grupos sociales en la tierra de Jorquera a mediados del siglo XVIII. Un espacio rural diferenciado (2011), y los artículos «Historia de mujeres y trabajo. Una propuesta didáctica par la enseñanza de la historia y el desarrollo de valores cívicos», Clío. History and 
History Teaching, 39 (2013), URL: http://clio.rediris.es, y «La construcción de la narrativa nacional española en los manuales escolares de Educación Primaria», Ensayos, 29 (1), (2014): 101-113.

Sebastián Molina Puche es Profesor Titular de Universidad de Didáctica de las Ciencias Sociales en la Universidad de Murcia. Licenciado en Geografía e Historia y doctor en Historia Moderna. Ha sido profesor TUI de Didáctica de las Ciencias Sociales en la Universidad de La Rioja, y previamente desarrolló un proyecto de investigación posdoctoral, financiado por el MEC, en la École des Hautes Études en Sciences Sociales de París. Sus últimas investigaciones se han encaminado a analizar la relación existente entre la enseñanza de la historia, el patrimonio y la creación de identidades culturales. De igual modo, ha participado en el diseño de materiales para la enseñanza de la historia. Entre sus numerosas publicaciones señalar la coedición de dos volúmenes titulados La evaluación en el proceso de enseñanza y aprendizaje de las ciencias sociales (2011) y La importancia de la historiografía en la enseñanza de la historia (2013). Respecto a los artículos, destacan «Family Histories and identities of integration. The use of family concept in history classroom in Spanish kindergarten and elementary school», The International Journal of Interdisciplinary Social Sciences, 6 (5), (2012): 169-184, y «History Education under the new Educational Reform: new wine in old bottles?», International Journal of Historical Learning, 12 (2), (2014): 122-132.

\section{Referencias:}

ABAD MERINo, Mercedes. «La frontera lingüística murciano-andaluza desde una perspectiva diacrónica». Tonos digital: Revista electrónica de estudios filológi$\cos 3$ (2002). Accessed May 10, 2016. http://www.um.es/tonosdigital/znum3/ estudios/LaFronteraPLANT.htm.

- Lenguas en contacto y cambio de lengua en una ciudad bilingüe: Orihuela, siglo XVII. Murcia: Universidad de Murcia, 1993.

AgüERa Ros, José Carlos. Pintura y sociedad en el siglo XVII. Murcia, un centro del Barroco español. Murcia: Real Academia Alfonso X el Sabio, 1994.

- Platería y plateros seiscentistas en Murcia. Murcia: Universidad de Murcia, 2005.

Álvarez Junco, José. Dioses útiles. Naciones y nacionalismos. Barcelona: Galaxia Gutenberg, 2016. 
Aragoneses, Manuel Jorge. Artes industriales cartageneras: lozas del siglo XIX. Cartagena: Museo Arqueológico Municipal, 1960.

- El mueble popular en Murcia (1866-1933). Consideraciones acerca de su entidad estética y funcional. Murcia: Academia Alfonso X el Sabio, 1982.

BARcA, Isabel. O pensamento histórico dos joves. Braga: Universidade do Minho, 2000.

BARTON, Keith. "Applied research: Educational research as a way of seeing». In The professional teaching of history: $U K$ and Dutch perspectives, edited by Allan McCully, Garry Mills and Carla van Boxtel, 1-15. Coleraine: History Teacher Education Network, 2012.

BaUtista VILAR, Juan. El proceso de vertebración territorial de la Comunidad de Murcia: de reino a autonomía uniprovincial. Murcia: Consejo Jurídico de la Región de Murcia, 2003.

Belda Navarro, Cristóbal, y Elías Hernández Albaladejo. Arte en la Región de Murcia. De la Reconquista a la Ilustración. Murcia: Editora Regional, 2006.

CALVANI, Antonio. L'insegnamento della storia nella scuola elementare. Florencia: La Nuova Italia, 1986.

Canals, Roser, y Neus González. «El Currículo de Conocimiento del Medio Social y Cultural, y la formación de competencias». In Didáctica del Conocimiento Social y Cultural en la Educación Primaria: ciencias sociales para aprender, pensar y actuar, edited by Antoni Santisteban and Joan Pagès. Madrid: Síntesis, 2011.

Cascales, Francisco. Discursos históricos de la Muy Noble y Muy Leal Ciudad de Murcia. Murcia: Luis de Berós, 1621.

Clark, Anna. «Whose History? Teaching Australia's contested past». Journal of Curriculum Studies 36 (5) (2004): 533-641.

Cooper, Hilary. History 3-11. Early Years and Primary. A guide for teachers. Londres: David Fulton Publishers, 2006.

Cuesta, Raimundo. Clío en las aulas. La enseñanza de la Historia en España entre reformas, ilusiones y rutinas. Madrid: Akal, 1998.

Delgado, Consuelo, y Catalina Albacete. Conocimiento del medio social y cultural. Murcia: Diego Marín, 2006.

Díez de Revenga, Francisco Javier, y Mariano de Paco. Historia de la literatura murciana. Murcia: Universidad de Murcia, Academia Alfonso X el Sabio y Editora Regional, 1989.

EGAN, Kieran. La comprensión de la realidad en la educación infantil y primaria. Madrid: Morata, 1991.

Estepa Giménez, Jesús, et al., "Análisis del patrimonio presente en los libros de texto: obstáculos, dificultades y propuestas». Revista de Educación 355 (2011): 573-589. 
Ferreras-Listán, Mario, y Roque Jiménez Pérez. “¿Cómo se conceptualiza el patrimonio en los libros de texto de Educación Primaria?». Revista de Educación 361 (2013): 591-618.

Franco Silva, Alfonso. El alumbre del Reino de Murcia. Una historia de ambición, intrigas, riqueza y poder. Murcia: Real Academia Alfonso X el Sabio, 1996.

García AviLÉs, José María. Los moriscos del Valle de Ricote. Alicante: Universidad de Alicante, 2007.

GARcía GonZÁlEz, Francisco, coord. La Guerra de Sucesión en España y la batalla de Almansa. Europa en la encrucijada. Madrid: Sílex, 2009.

GARcía PuCHOL, Joaquín. Los textos escolares de historia en la enseñanza española (1808-1900). Análisis de su estructura y contenido. Barcelona: Universidad de Barcelona, 1992.

Gómez CARrasco, Cosme Jesús. «Pensamiento histórico y contenidos curriculares en los libros de texto. Un análisis exploratorio de la Edad Moderna en 2. ${ }^{\circ}$ de ESO». Ensayos 29 (1) (2014): 131-158.

Gómez Carrasco, Cosme J., Raimundo A. Rodríguez Pérez y Pedro Miralles MARTínEZ. «La enseñanza de la historia en Educación Primaria y la construcción de una narrativa nacional. Un estudio sobre exámenes y libros de texto en España». Perfiles Educativos 37 (150) (2015): 20-38.

GutiÉRREZ-CORTINES CORRAL, Cristina. Renacimiento y arquitectura religiosa en la antigua diócesis de Cartagena (Reyno de Murcia, Gobernación de Orihuela y Sierra del Segura). Murcia: Colegio de Aparejadores y Arquitectos Técnicos, 1987.

JimÉnEz AlCÁzAR, Juan Francisco. «Identificación e identidad en el desarrollo de la memoria histórica: el reino de Murcia y la Edad Media». Historia y Genealogía 2 (2012): 175-199.

Jiménez Castillo, Pedro. «Murcia. De la Antigüedad al Islam». PhD diss., Universidad de Granada, 2013.

LEE, Peter, and Rosalyn AsBHY. «Progression in Historical Understanding among Students ages 7-14». In Knowing, Teaching and Learning History. National and International Perspectives, edited by Peter N. Stearns, Peter Seixas and Sam Wineburg, 199-222. Nueva York-Londres: New York University Press, 2000 .

LÉVEsque, Stéphane. Thinking Historically. Educating Students for the 21th Century. Toronto: Toronto University Press, 2008.

Llull, Vicente, et al., "Proyecto La Bastida”: economía, urbanismo y territorio de una capital argárica». Verdolay: Revista del Museo Arqueológico de Murcia 13 (2011): 57-70.

LÓPEZ FACAL, Ramón. «La LOMCE y la competencia histórica». Ayer 94 (2014): 273-285. 
LÓPEZ FACAL, Ramón. «Nacionalismos y europeísmos en los libros de texto: identificación e identidad nacional». Clío y asociados: la historia enseñada 14 (2010): 11-13.

Martínez Valcárcel, Nicolás. "El uso de los manuales escolares de historia de España. Análisis de resultados desde la propuesta de Schulman». Íber: Didáctica de las ciencias sociales, geografía e historia 70 (2011): 44-58.

Martínez Valcárcel, Nicolás, Xosé Manuel Souto GonzÁlez y José Beltrán LlaVADOR. «Los profesores de historia y la enseñanza de la historia en España. Una investigación a partir de los recuerdos de los alumnos». Enseñanza de las Ciencias Sociales 5 (2006): 55-71.

Medioni, María-Alice. El Cantón de Cartagena. Madrid: Siglo XXI, 1979.

MERCHÁn, Francisco Javier. Enseñanza, examen y control: profesores y alumnos en clase de historia. Barcelona: Octaedro, 2005.

Miralles Martínez, Pedro, y Nicolás Martínez Valcárcel. "La fase de desarrollo de la clase de Historia en bachillerato». Revista Iberoamericana de Educación 46 (1) (2008): 1-10.

Molina Puche, Sebastián. «El gobierno de un territorio de frontera: corregimiento y corregidores de Chinchilla, Villena y las nueve villas, 1586-1690». Investigaciones históricas 25 (2005): 55-84.

Monteagudo Fernández, J., Pedro Miralles Martínez y José Luis Villa AroCENA, Evaluación de la materia de Historia. El caso de la Región de Murcia. Saarbrücken: Publicia, 2014.

OsBorne, Ken. «Teaching history in schools: A Canadian debate». Journal of Curriculum Studies 35 (5) (2003): 585-626.

PÉrez PicAzo, María Teresa, y Guy LEMEunier. El proceso de modernización en la Región murciana (siglos XVI-XIX.) Murcia: Editora Regional, 1984.

Pérez Picazo, María Teresa, Guy Lemeunier y Francisco Chacón Jiménez. Materiales para una historia del Reino de Murcia en los tiempos modernos. Murcia: Universidad de Murcia, 1979.

PÉREz RoJAS, Francisco Javier. Cartagena 1874-1936 (Transformación urbana y arquitectura). Murcia, Editora Regional, 1986.

PÉrez SÁnchez, Manuel. El arte del bordado y del tejido en Murcia, siglos XVI-XIX. Murcia: Universidad de Murcia, 1999.

PRATS, Joaquim. «Criterios para la elección del libro de texto de historia». Íber: Didáctica de las ciencias sociales, geografía e historia 70 (2011): 7-13.

- «Hacia una definición de la investigación en Didáctica de las Ciencias Sociales». Enseñanza de las Ciencias Sociales 1 (2002): 81-89.

Ramallo, Sebastián F., y María Milagrosa Ros. «De "Qart Hadast” a "Carthago Nova”: la conquista de Escipión como trasfondo». In Los Escipiones: Roma 
conquista Hispania, edited by Manuel Bendala Galán, 163-179. Madrid: Museo Arqueológico Regional de Alcalá de Henares, 2015.

RoBles FERnÁNDEZ, Alfonso. «Estudio arqueológico de los palacios andalusíes de Murcia (ss. X-XV). Tratamiento ornamental e influencia en el entorno». PhD diss., Universidad de Murcia, 2016.

Rodríguez GARRIDo, Juan Esteban. «Trato y maltrato de la Historia de España en los libros de la EGB y la ESO». PhD diss., Universidad Complutense de Madrid, 2011.

Rodríguez Llopis, Miguel, dir. y José Miguel Martínez CARrión, coord. Atlas histórico ilustrado de la Región de Murcia y su antiguo reino. Murcia: Fundación Séneca, 2006.

Rodríguez Llopis, Miguel. Historia de la Región de Murcia. Murcia, Editora Regional, 1994.

Rodríguez PÉREz, Raimundo A. El camino hacia la corte. Los marqueses de Los Vélez en el siglo XVI. Madrid: Sílex, 2011.

Rodríguez PÉrez, Raimundo A., y María del Mar Simón García. «La construcción de la narrativa nacional española en los manuales escolares de Educación Primaria». Ensayos 29 (1) (2014): 101-113.

Rodríguez Pérez, Raimundo A., Cosme Jesús Gómez Carrasco y María del Mar Simón GARCÍA. «Conocimiento y pensamiento histórico en los manuales escolares de tercer ciclo de Primaria. Un análisis comparativo». In Investigación educativa en Educación Primaria, edited by Rosa Nortes Martínez-Artero and José Ignacio Alonso Roque, 369-380. Murcia: Editum, 2014.

RUIz MARTín, Felipe. Los alumbres españoles: un índice de la coyuntura económica europea en el siglo XVI. Madrid: Fundación Española de Historia Moderna, 2005.

SÁiz SERRANo, Jorge. «Educación histórica y narrativa nacional». PhD diss. Universidad de Valencia, 2015.

SÁiz Serrano, Jorge, y Juan Carlos Colomer Rubio. "¿Se enseña pensamiento histórico en los libros de texto de Educación Primaria? Análisis de actividades de historia para alumnos de 10-12 años de edad». Clío. History and History Teaching 40 (2014). Accessed June 25, 2016. http://clio.rediris.es.

SÁnchez IbáÑEz, Raquel, y Alejandro Martínez Nieto. «Patrimonio e identidad de la Región de Murcia: una aproximación a través del currículo y los libros de texto de Ciencias Sociales de Secundaria». Clio. History and History Teaching 41 (2015). Accessed May 13, 2016. http://clio.rediris.es.

SÁnchez Moreno, José. Vida y obra de Francisco Salzillo. Una escuela de escultura en Murcia. Murcia: Nogués, 1945. 
Segado Bravo, Pedro. Lorca Barroca. Arquitectura y arte. Murcia: Editum, 2012.

SHEMILT, Dennis. «Beauty and the philosopher: Empathy in history and classroom». In Learning history, edited by Alaric Dickinson, Peter Lee and Peter Rogers, 3984. Londres: Heinemann Educational Books, 1984.

SolÉ, Glória. «O manual escolar no ensino primário em Portugal: perspectiva histórica e análise do ensino da História a través deste recurso didáctico». Ensayos 29 (1) (2004): 43-64.

Torres Fontes, Juan. Don Pedro Fajardo, Adelantado Mayor del Reino de Murcia. Madrid: CSIC, 1953.

- Repartimiento de Murcia. Murcia: Academia Alfonso X el Sabio, 1960.

- Fajardo el Bravo. Murcia: Universidad de Murcia, 1944.

- Repartimiento de Lorca. Murcia: Ayuntamiento de Lorca y Academia Alfonso X el Sabio, 1977.

VAlls MontÉs, Rafael. "La presencia del Islam en los actuales manuales españoles de historia». Íber. Didáctica de las ciencias sociales, geografía e historia 20 (2011): 59-66.

- «Los estudios sobre manuales escolares de historia y sus nuevas perspectivas». Didáctica de las ciencias experimentales y sociales 15 (2001): 23-36.

- Historia y memoria escolar. Segunda República, Guerra Civil y dictadura franquista en las aulas. Valencia: PUV, 2009.

- Historiografía escolar española: siglos XIX-XXI. Madrid: UNED, 2007.

VIÑao Frago, Antonio. Escuela para todos. Educación y modernidad en la España del siglo XX. Madrid: Marcial Pons, 2004.

- Política y educación en los orígenes de la España contemporánea. Examen especial de sus relaciones en la enseñanza secundaria. Madrid: Siglo XXI, 1982.

Wineburg, Sam. Historical Thinking and Other Unnaturals Acts: Charting the Future of Teaching the Past. Philadelphia: Temple University Press, 2001. 